\title{
RELAPSING POLYCHONDRITIS: A CASE REPORT
}

\section{Carla Luchese de Almeida ${ }^{1, *}$, Guilherme Poletto Hess Pretto', Isabela Calixto Maluf', Isabela Stocco, Thiago Alberto Fernandes Gomes dos Santos ${ }^{1}$, Thelma Larocca Skare ${ }^{1}$}

1. Hospital Evangélico Mackenzie de Curitiba, Curitiba (PR), Brazil.

*Corresponding author: cah_luchese@hotmail.com

\section{BACKGROUND}

Relapsing polychondritis (RP) is a unique, rare autoimmune disorder in which the cartilaginous tissues are the primary targets of destruction and the immune damage can spread to proteoglycan-rich structures (eyes, heart, blood vessels, and inner ear). The damage can involve noncartilaginous tissues, such as the kidney and blood vessels. Pathogenesis is still unclear. It may occur in a primary form or it may be associated with other diseases.

\section{CASE REPORT}

A 42-year-old Caucasian woman was referred to our service in 2018 with lumbar, costal and arms pain, progressive dyspnea and ventilatory-dependent pain. She had received immunoglobulin with no response but responded partially to oral prednisone (80 mg/day). She had saddle nose (Fig. 1), ear chondritis, dyspnea and stridor at rest. Bronchoscopy showed bronchomalacia, tracheomalacia and subglottic malacia. Spirometry revealed a severe obstructive ventilatory disorder with no response to bronchodilator. With sequential negative antineutrophil cytoplasmic antibodies (ANCA) exams, relapsing polychondritis (RP) was the first suspicion, and cyclophosphamide $1 \mathrm{~g} / \mathrm{month}$ was started and used for 12 months with partial response. Tracheostomy was performed for suspected pneumonia. Her ventilatory condition worsened with increased secretion and complaints of feeling tired. No response to azathioprine was observed and she was started on mycophenolate mofetil $3 \mathrm{~g} /$ day since 2019 with partial response.

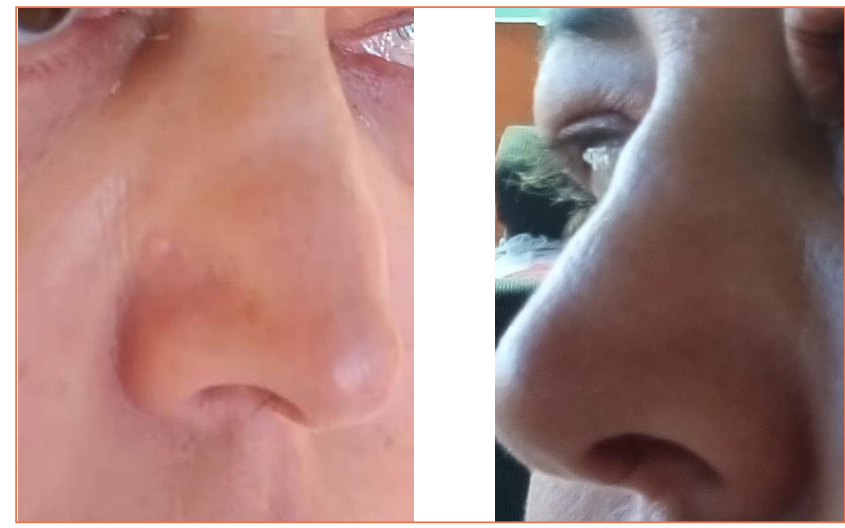

Figure 1. Patient's saddle nose.

\section{CONCLUSION}

Knowledge about the manifestations of RP and its management continues to evolve. Further studies with long-term follow-up are required to assess the best medical and interventional treatment options for these patients. 